\title{
ANATOMIA DO LENHO DE MIMOSA PIGRA BENTH. ${ }^{1}$
}

\author{
PAULO FERNANDO DOS SANTOS MACHADO² \\ JOSÉ NEWTON CARDOSO MARCHIORI ${ }^{3}$
}

\section{RESUMO}

O lenho de Mimosa pigra é anatomicamente descrito e ilustrado com fotomicrografias, sendo sua estrutura comparada com a de espécies de outros táxons infragenéricos.

Palavras-chave: anatomia da madeira, Fabaceae, Leguminosae, Mimosa pigra, Mimosoideae.

\section{ABSTRACT}

[Wood anatomy of Mimosa pigra Benth.].

The wood of Mimosa pigra is anatomically described and illustrated with photomicrographs, being its structure compared with species of other infrageneric taxa.

Key words: Fabaceae, Leguminosae, Mimosa pigra, Mimosoideae, wood anatomy.

\section{INTRODUÇÃO}

Espécie ripária e de ampla distribuição natural na América do Sul, Mimosa pigra L. dispõe, apenas, de escassas referências à estrutura anatômica do seu lenho. O presente trabalho visa sanar essa lacuna, oferecendo uma detalhada descrição microscópica do lenho, ilustrada com fotomicrografias. A estrutura anatômica é comparada com a de outras espécies do mesmo gênero, com vistas a uma abordagem taxonômica.

\section{REVISÃO DE LITERATURA}

Arbusto vigoroso, de 1-3 m de altura, $\mathrm{Mi}$ mosa pigra L. apresenta ramos ascendentes ou eretos, revestidos de setas bronzeadas, com acúleos recurvos dispersos e grandes folhas dísticas, sensíveis ao toque, compostas de 5-15 pares de pinas; os lomentos, de 5-10 cm de comprimento e 1-1,5 cm de largura, também apresentam setas bronzeadas, tanto em suas faces

1 Recebido em 05-6-2016 e aceito para publicação em 21-7-2016.

2 Engenheiro Florestal, doutorando do Programa de PósGraduação em Engenharia Florestal, Universidade Federal de Santa Maria. Santa Maria, RS, Brasil. barcasole@gmail.com

3 Engenheiro Florestal, Dr. Bolsista de Produtividade em Pesquisa (CNPq - Brasil). Professor Titular do Departamento de Ciências Florestais, Universidade Federal de Santa Maria. planas como no replo e reúnem 7-21 segmentos retangulares, indeiscentes, de 2-6 $\mathrm{mm}$ de comprimento por 7-15 $\mathrm{mm}$ de largura (Burkart, 1987).

Planta típica da margem de rios, Mimosa pigra é a espécie de mais ampla dispersão no gênero Mimosa, uma vez que sua distribuição natural se estende da parte tropical do México e Antilhas até o delta do rio Paraná e ilha de Martin Garcia (Burkart, 1948), ocorrendo sempre à margem de rios e estuários, em altitudes de até $150 \mathrm{~m}$ e sobre solos barrentos ou arenosos (Barneby, 1991). No Uruguai, a distribuição da espécie restringe-se à mata ciliar do rio de mesmo nome (Santander \& González, 2007); no Rio Grande do Sul, embora não incluída por Rambo (1966) entre as Leguminosas autóctones, é igualmente nativa no Oeste do estado. $\mathrm{O}$ epíteto latino "pigra", que tem o significado de lenta ou preguiçosa, deve-se ao fato de Linnaeus ter considerado a espécie pouco sensível ao toque, comparada a Mimosa pudica, espécie-tipo do gênero (Burkart, 1948).

No tocante à taxonomia, Bentham (1876) classificou Mimosa pigra na seção Habbasia DC. e série Asperatae Benth., em sua contribuição à "Flora Brasiliensis". Barneby (1991), por sua vez, incluiu a mesma na seção Habbasia DC. e série Habbasia, juntamente com outras 9 
espécies de regiões úmidas ou temporariamente úmidas e de terras baixas no continente americano, desde a região do Golfo do México e Índias Ocidentais, até o norte da Argentina e Uruguai; a única exceção no referido grupo é Mimosa pellita Humb. \& Bonpl. ex Willd., espécie de ampla distribuição na África tropical e ilha de Madagascar.

Para o lenho de Mimosa pigra, Cozzo (1951) refere: poros de contorno angular, solitários e em múltiplos curtos; pontoações intervasculares grandes; pontoações raio-vasculares e parênquimo-vasculares semiareoladas; raios unisseriados, com poucos bisseriados e 9 (2-35) células de altura; células radiais eretas, com pontoações bem visíveis; e parênquima axial de difícil visualização, com abundantes células fusiformes.

\section{MATERIAL E MÉTODOS}

$\mathrm{O}$ material em estudo, coletado à margem ciliar do Rio Uruguai, foi depositado no Herbário e Xiloteca do Departamento de Ciências Florestais (HDCF) da Universidade Federal de Santa Maria com os seguintes registros: HDCF 7374, Mimosa pigra L.; leg.: Kettenhuber, P.L.W., 27-03-2016, Itá (SC, Brasil), com frutos; det.: Marcos Sobral.

Da amostra de madeira foram extraídos três corpos-de-prova $(1 \times 2 \times 3 \mathrm{~cm})$, orientados para a obtenção de cortes anatômicos nos planos transversal, longitudinal radial e longitudinal tangencial; um quarto bloquinho foi também preparado, com vistas à maceração.

A confecção de lâminas de cortes anatômicos seguiu a metodologia descrita em Burger \& Richter (1991), usando-se, como corantes, uma mistura de Acridina-Vermelha e Crisoidina num primeiro banho, e Azul-de-Astra no segundo (Dujardin, 1964). Para as lâminas de macerado adotou-se o método de Jeffrey (Freund, 1970) e coloração da pasta de fibras com Safranina. Com vistas ao preparo de lâminas permanentes, usouse "Entellan" em ambos os tipos de lâminas.

As descrições basearam-se nas recomendações do IAWA Committee (Wheeler et al., 1989).
Na determinação da percentagem dos tecidos e da largura de raios em número de células foram realizadas 600 determinações ao acaso, com auxílio de contador de laboratório, conforme proposto por Marchiori (1980). A frequência de poros foi obtida a partir de um quadrado de área conhecida, superposto a fotomicrografias em diferentes pontos da seção transversal.

As medições da estrutura anatômica foram realizadas em microscópio fotônico Carl Zeiss, no Laboratório de Anatomia da Madeira da Universidade Federal de Santa Maria. As imagens que ilustram o texto foram tomadas em fotomicroscópio Leica DM 1000, equipado com câmera digital Olympus Camedia CX 40, no Laboratório de Anatomia da Madeira do Centro de Educação Superior Norte do Rio Grande do Sul (CESNORS - UFSM), em Frederico Westphalen, RS. Na citação de características quantitativas, os números entre parênteses correspondem aos valores mínimos e máximos observados; o valor que acompanha a média é o desvio padrão.

\section{DESCRIÇÃO DA MADEIRA}

Anéis de crescimento: indistintos.

Vasos: extremamente numerosos (30 \pm 5 (2038) poros $/ \mathrm{mm}^{2}$ ), ocupando $11 \pm 2,5 \%$ do volume da madeira. Porosidade difusa. Poros solitários $(62 \%)$, menos comumente em múltiplos radiais de $2-10$ (24\%) e em múltiplos racemiformes de 3-14 (14\%), de seção geralmente poligonal $(75 \pm 22(30-118) \mu \mathrm{m})$ e paredes finas a espessas $(3,9 \pm 1,1(2,5-6,2) \mu \mathrm{m})$ (Figura 1A, B). Elementos vasculares curtos (247 \pm 39 (190-340) $\mu \mathrm{m})$, com placas de perfuração simples, oblíquas ou transversais ao vaso, desprovidos de apêndices ou com apêndices curtos $(21 \pm 11(10-40) \mu \mathrm{m})$. Pontoações intervasculares pequenas e arredondadas $(6,2 \pm$ $0,8(5,2-7,2) \mu \mathrm{m})$, alternas, ornamentadas, com abertura em fenda inclusa, por vezes coalescente (Figura 1F). Pontoações raio-vasculares, semelhantes às intervasculares, mas menores $(4,8 \pm$ $0,5(3,6-5,2) \mu \mathrm{m})$. Espessamentos espiralados, ausentes; conteúdos, presentes. 

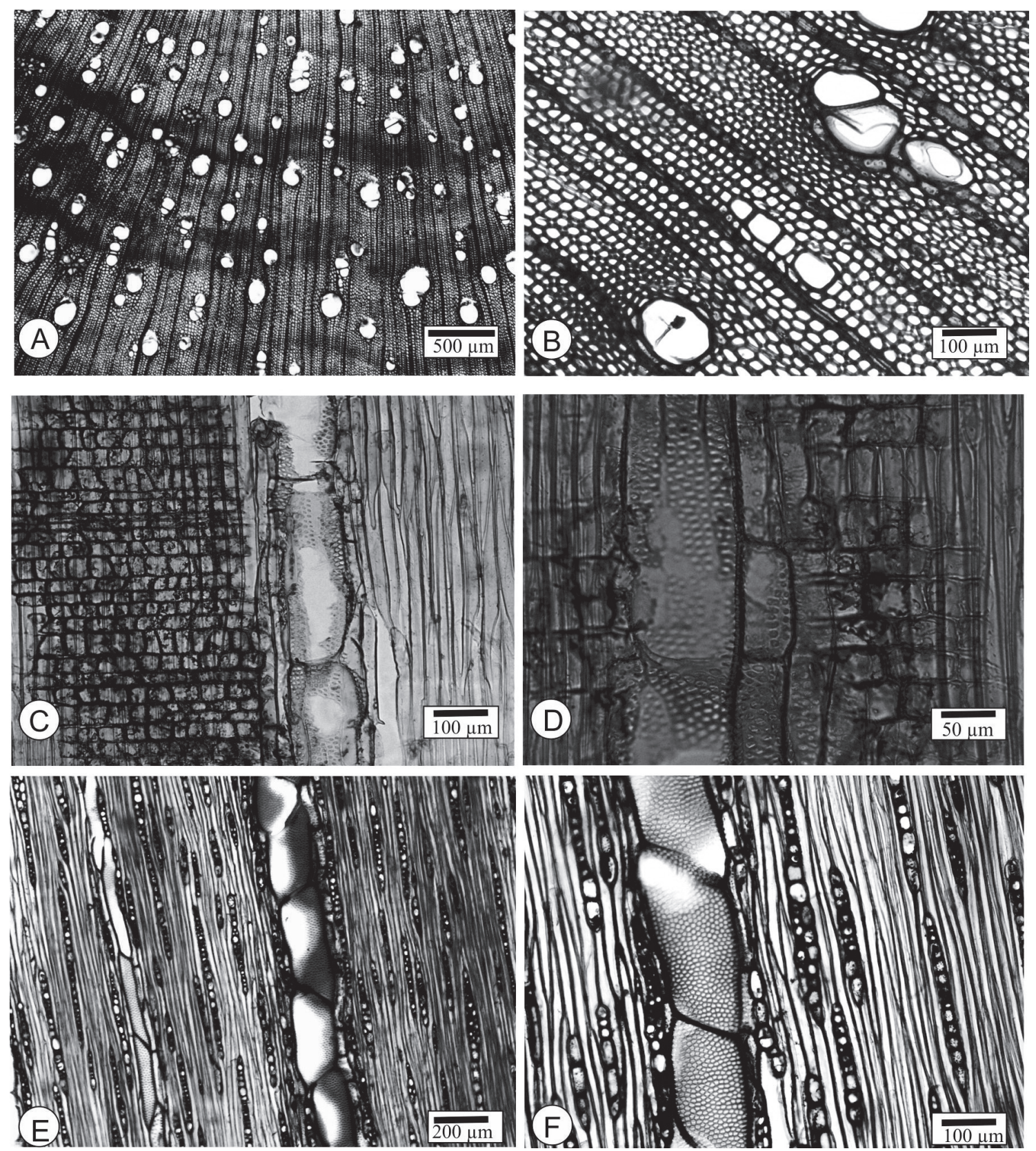

FIGURA 1 - Detalhes anatômicos do lenho de Mimosa pigra L. A, B - Anéis de crescimento indistintos, porosidade difusa e em múltiplos de poucas unidades (seção transversal). C, D - Raios heterogêneos, com células quadradas, eretas e procumbentes (seção longitudinal radial). E, F - Raios unisseriados, menos comumente bisseriados, e pontoações intervasculares alternas (seção longitudinal tangencial). 
Parênquima axial: de difícil visualização em plano transversal, representando $9 \pm 3,8 \%$ do volume da madeira; paratraqueal vasicêntrico, por vezes unilateral e em faixas tangenciais que se estendem por vários raios, simulando anel de crescimento. Células fusiformes de $231 \pm 28$ (175-275) $\mu \mathrm{m}$ de altura. Séries parenquimáticas de $258 \pm 29$ (213-325) $\mu \mathrm{m}$ de altura, com duas, raro três células. Cristais romboédricos abundantes, em séries dispostas, sobretudo, no contato com fibras.

Raios: muito numerosos (10 $\pm 0,9$ (9-12) raios/mm), ocupando $21 \pm 2,3 \%$ do volume da madeira (Figura 1E, F); estreitos (27 \pm 6 (1845) $\mu \mathrm{m})$ e heterogêneos, compostos de células quadradas, eretas e procumbentes (Figura 1C, D). Os unisseriados, predominantes $(75 \%)$, de $152 \pm 64$ (55-275) $\mu \mathrm{m}$ e 2-18 células de altura. Os multisseriados, em sua quase totalidade bisseriados $(21 \%)$, menos comumente trisseriados (4\%); de $331 \pm 146(150-825) \mu \mathrm{m} \mathrm{e}$ 9-37 células de altura. Células radiais de contorno arredondado ou poligonal, em plano tangencial. Células envolventes, células radiais de paredes disjuntas e células perfuradas, ausentes. Raios fusionados e conteúdos, presentes.

Fibras: libriformes, de $676 \pm 88$ (550-950) $\mu \mathrm{m}$ de comprimento, com $16 \pm 3(10-23) \mu \mathrm{m}$ de largura e paredes finas a espessas $(2,5 \pm 0,7$ (1,3$3,8) \mu \mathrm{m}$ ), ocupando $59 \pm 5 \%$ do volume da madeira (Figura 1B). Fibras gelatinosas, abundantes; espessamentos espiralados, fibras septadas e traqueídeos, ausentes.

Outros caracteres: variantes cambiais, tubos laticíferos e taniníferos, canais intercelulares, células oleíferas, células mucilaginosas e estratificação, ausentes; máculas medulares, não observadas.

\section{ANÁLISE DA ESTRUTURA ANATÔMICA \\ O lenho de Mimosa pigra reúne alguns caracteres anatômicos de ampla ocorrência em Leguminosas Mimosóideas (Fabaceae Mimosoideae), tais como: porosidade difusa, placas de perfuração simples, pontoações arre-}

dondadas, ornamentadas e em arranjo alterno, parênquima paratraqueal, e fibras libriformes.

Em estudo do lenho de 13 espécies argentinas de Mimosa, Cozzo (1951) observou uma ampla variação anatômica entre as mesmas, agregando que inexiste um traço anatômico "comum que as enlace". O autor resumiu suas observações definindo o gênero como "estruturalmente heterogêneo", uma vez que a variabilidade encontrada corresponde ao observado em toda a subfamília Mimosoideae. Em sua chave para identificação de espécies, Cozzo (1951) segregou Mimosa pigra pela ocorrência de raios "quase exclusivamente" unisseriados, com poucos bisseriados, bem como pela presença de células radiais eretas e de poros solitários ou em curtos múltiplos radiais, sem múltiplos racemiformes.

A respeito dos raios, o material em estudo exibe células radiais quadradas, eretas e procumbentes, discordando, neste aspecto, da referência exclusiva a células eretas, feita por Cozzo (1951) para a mesma espécie. Essa divergência com relação à forma das células radiais poderia ser justificada se o autor argentino houvesse examinado caule jovem, visto que, na ontogenia dos raios, as células eretas precedem a formação de células quadradas e procumbentes. De todo modo, em Mimosa pigra os raios são nitidamente heterogêneos, ao contrário do descrito para Mimosa cruenta (Marchiori, 1985), Mimosa uraguensis (Marchiori 1996b) e Mimosa trachycarpa (Marchiori, 1997), espécies vinculadas à série Stipellares Benth. e seção Batocaulon DC.

Raios heterogêneos, todavia, não constituem raridade em Mimosa L., constando, igualmente, nos lenhos de Mimosa parvipinna e $M$. ramulosa, da subsérie Obstrigosae (Benth.) Barneby (Machado \& Marchiori, 2016).

Sobre essa questão, resta salientar que Metcalfe \& Chalk (1972) afirmam que os raios de Mimosaceae são os mais especializados da família Leguminosae (Fabaceae). BarettaKuipers (1981), por sua vez, refere que a estrutura do lenho em Leguminosae progrediu em 
dois rumos distintos, a partir da relativamente primitiva subfamília Caesalpinioideae: em direção a Mimosoideae, pela especialização dos raios, e em direção a Papilionoideae, pela estratificação de todos os elementos. Nesse contexto, pode-se afirmar que o lenho de Mimosa pigra é um dos mais primitivos no gênero e subfamília a que pertence.

A predominância de raios unisseriados no material em estudo (75\%), por sua vez, confirma referência anterior de Cozzo (1951) e mostra-se valiosa para a identificação da espécie, visto sua escassa ocorrência em madeiras do gênero Mimosa.

A predominância de poros solitários e em curtos múltiplos, descrita para Mimosa pigra, parece ser caráter majoritário em Mimosa L., constando na literatura, entre outras espécies, para Mimosa berroi (Marchiori, 1996a), M. bimucronata (Marchiori, 1993), M. eriocarpa (Carnieletto \& Marchiori, 1993), M. pilulifera (Marchiori \& Muñiz, 1997b) e M. scabrella (Marchiori, 1982). O mesmo caráter anatômico, por sua vez, permite segregar Mimosa pigra e as espécies anteriormente citadas, de Mimosa cruenta (Marchiori, 1985), M. uraguensis (Marchiori, 1996b), M. trachycarpa (Marchiori \& Muñiz, 1997), M. barnebiana e M. bifurca (Machado et al., 2016), que pertencem à série Stipellares Benth.

A abundância de fibras gelatinosas no lenho, observada no presente estudo, é freqüente em espécies reófilas, de acordo com Denardi (2007), e condizente, portanto, com o hábito escandente e ripário de Mimosa pigra.

Como única espécie da seção Habbasia DC. e série Habbasia (sensu Barneby, 1991; série Asperatae, segundo Bentham, 1876) até o momento descrita, resultam prematuras maiores considerações taxonômicas e filogenéticas do lenho.

\section{REFERÊNCIAS BIBLIOGRÁFICAS}

BARNEBY, R.C. Sensitivae censitae. A description of the Genus Mimosa Linnaeus (Mimosaceae) in the New World. Memoirs of the New York Botanical Garden, v. 65, p. 1-835, 1991.

BENTHAM, G. Leguminosae. III Mimoseae. In: MARTIUS, C.F.P. von. Flora Brasiliensis. 1876. v. 15 , fasc. 2 , p. 259-527.

BURGER , L.M.; RICHTER, H.G. Anatomia da Madeira. São Paulo: Ed. Nobel, 1991. 154 p.

BURKART, A. Las especies de Mimosa de la Flora Argentina. Darwiniana, San Isidro, v. 8, n. 1, p. 231, 1948.

BURKART, A. Fam. 83. Leguminosae (= Fabaceae), Leguminosas. In: BURKART, A.; BURKART, N.S.T. de; BACIGALUPO, N.M. Flora Ilustrada de Entre Rios (Argentina). Buenos Aires, Colleción Cientifica del I.N.T.A., 1987, tomo VI, III. p. 442-738.

COZZO, D. Anatomia del leño secundario de las Leguminosas Mimosoideas y Caesalpinioideas argentinas silvestres y cultivadas. Revista del Instituto Nacional de Investigación de las Ciencias Naturales, Ciencias Botánicas, v. 2, n. 2, p. 63-146, 1951.

CARNIELETTO, C.; MARCHIORI, J.N.C. Anatomia da madeira de Mimosa eriocarpa Benth. $\mathrm{Ci}$ ência Florestal, Santa Maria, v. 3, n. 1, p. 107120, 1993.

DENARDI, L. Anatomia e flexibilidade do caule de quatro espécies lenhosas para o manejo biotécnico de cursos de água. Tese (Doutorado em Engenharia Florestal). Santa Maria: Universidade Federal de Santa Maria, 2007. 112 f.

DUJARDIN, E.P. Eine neue Holz-Zellulosenfaerbung. Mikrokosmos, n. 53, p. 94, 1964.

FREUND, H. Handbuch der Mikroskopie in der Technik. Frankfurt: Umsham Verlag, 1970. 375 p.

MACHADO, PF dos S.; MARCHIORI, J.N.C.; BALDIN, T. Anatomia da madeira de duas espécies de Mimosa da série Stipellares Benth. Balduinia, Santa Maria, n. 54, p. 1-10, 2016.

MARCHIORI, J.N.C. Estudo anatômico do xilema secundário e da casca de algumas espécies dos gêneros Acacia e Mimosa, nativas no estado do Rio Grande do Sul. Dissertação (Mestrado em Engenharia Florestal). Curitiba: Universidade Federal do Paraná, 1980. 186 f.

MARCHIORI, J.N.C. A estrutura do xilema secundário de Mimosa daleoides Benth. (Leguminosae Mimosoideae). Ciência e Natura, Santa Maria, n. 4, p. 107-113, 1982. 
MARCHIORI, J.N.C. Anatomia da madeira e casca do maricá, Mimosa bimucronata (DC.) O. Kuntze. Ciência Florestal, Santa Maria, v. 3, n. 1, p. 85-106, 1993.

MARCHIORI, J.N.C. Anatomia da madeira e casca da bracatinga, Mimosa scabrella Benth. Ciência e Natura, Santa Maria, n. 17, p. 115-132, 1995.

MARCHIORI, J.N.C. Anatomia do xilema secundário de Mimosa berroi Burkart. Ciência e Natura, Santa Maria, n. 118, p. 117-129, 1996a.

MARCHIORI, J.N.C. Anatomia do xilema secundário de Mimosa uraguensis Hook. \& Arn. Ciência e Natura, Santa Maria, n. 18, p. 103-115, 1996b.

MARCHIORI, J.N.C.; MUÑIZ, G.I.B. de. Estudo anatômico do xilema secundário de Mimosa trachycarpa Benth. Ciência Rural, Santa Maria, v. 27, n. 2, p. 223-228, 1997a.

MARCHIORI, J.N.C.; MUÑIZ, G.I.B. de. Estudo anatômico do xilema secundário de Mimosa pilulifera Benth. Ciência Florestal, Santa Maria, v. 7, n. 1, p. 65-75, 1997 b.

RAMBO, B. Leguminosae Riograndenses. Pesquisas, Botânica, Instituto Anchietano de Pesquisas, São Leopoldo, n. 23, p. 1-166, 1966 (separata).

SANTANDER, C.A.B.; GONZÁLEZ, I.A.G. Flora arbórea del Uruguay. Con énfasis en las espécies de Rivera y Tacuarembó. Montevideo: Cofusa, 2007, 542 p.

WHEELER, E.A.; BAAS, P.; GASSON, P.E. IAWA list of microscopic features for hardwood identification. IAWA Bulletin, v. 10, n. 3, p. 218359, 1989. 